\title{
"Nuestros únicos maestros son aquellos que nos dicen: "haz junto conmigo": aproximaciones a una idea de educación en Diferencia y repetición de Gilles Deleuze
}

\author{
Juan Camargo \\ Universidad de la Salle \\ camargo11@unisalle.edu.co \\ https://orcid.org/0000-0003-4007-4525
}

Resumen: En la bibliografia más reciente en torno a la obra filosófica de Deleuze no se ha abordado la relación entre una idea de educación y su libro Diferencia y repetición. Este artículo explora e interpreta a partir de la ontologia de Deleuze una idea de formación. Parte de la comprensión de sus ideas de "diferencia y repetición" y del "método de dramatización" me permiten pensar cómo estas se inscriben en el terreno educativo, cuáles son sus alcances y consecuencias, ideas que me llevan, por lo demás, a retomar los temas de la emancipación intelectual y la igualdad de la mano de Joseph Jacotot y Jacques Rancière.

Palabras clave: diferencia intensiva; dramatización; maestro-tirano; método; igualdad de las inteligencias

Abstract: "Our Only Teachers Are Those Who Tell Us: 'Do Together with Me"': Approaches to an Idea of Education in Difference and Repetition by Gilles Deleuze". In the most recent bibliography about Deleuze's philosophical work, there is no research that studies the relationship between an idea of education and his book Difference and Repetition. This article explores and interprets, based on the ontology of Deleuze, an idea of education. The understanding of the concepts of "difference and repetition" and "the dramatization method", allows me to think how to inscribe them in the educational field, which are their consequences and what is their scope. These ideas invite us to return to the themes of intellectual emancipation and equality, based on Jacotot's and Renciere's works.

Keywords: intensive difference; dramatization; tyrant teacher; method; equality od intelligences 


\section{Introducción}

Ante la demanda de cientificidad que normaliza las prácticas sociales y los saberes como formas de instrumentalización al servicio de un modelo económico y social $^{1}$, es necesario (re)pensar, para el caso de las humanidades, una nueva forma de compresión del mundo y de sus relaciones sociales. Aquellas pretensiones explicativas de la ciencia se muestran inadecuadas cuando se quieren dos cosas. En primer lugar, mostrar la riqueza de las ciencias humanas, ese potencial artístico y creativo que engloba un modo de ser experiencial y acontecimental; en segundo lugar, cuando se quiere formar sujetos singulares y diferentes, no homogéneos al servicio de prácticas alienantes que disminuyen toda capacidad reflexiva. Si se asume que el ámbito en el que las humanidades toman fuerza y adquieren un papel relevante es el de la enseñanza o la formación, es acertado cuestionar el alcance actual del saber pedagógico y de los procesos educativos. P. Freire ${ }^{2}$, J. Martínez ${ }^{3}$, De Sousa Santos ${ }^{4}$ y G. Bula ${ }^{5}$ afirman que el modelo actual de educación apunta a reproducir formas de educación empresarial o de mercado, donde se producen individuos consumidores, listos para asumir las demandas del mercado. Así, ¿qué implicaría una educación que no reproduzca estas prácticas instrumentales y bancarias? ¿Cómo pensar una educación ética de la diferencia que supere el modelo actual de educación?

El presente artículo se propone discutir posibles caminos en torno a esta discusión. La propuesta parte de la interpretación de una idea de educación que conciba la formación de sujetos diferentes, cuyos intereses estén orientados no a reproducir formas de alienación y dominación, sino a crear escenarios de "individuación" donde se exploren formas inmanentes al desarrollo de sus vidas y de las potencias de sus cuerpos. Todo esto se hace a partir de los conceptos claves de Diferencia y repetición, libro que constituye para Deleuze su primer intento de "hacer filosofia"6. Es preciso dejar en claro que no se pretende

\footnotetext{
Habermas, J., Ciencia y técnica como ideología, Madrid: Tecnos, 1994.

Freire, Pedagogía del oprimido, México D.F.: Siglo Veintiuno, 1970.

Martinez, J.E., La universidad productora de productores: entre biopolitica y subjetividad, Bogotá: Universidad de la Salle, 2010.

4 De Sousa Santos, B., La universidad en el siglo XXI, Buenos Aires: Miño y Dávila, 2011.

5 Bula, G., Spinoza: educación para el cambio, Bogotá: Aula de humanidades, 2017.

6 Deleuze, G., Dos regimenes de locos: textos y entrevistas (1975-1995), Valencia: Pre-textos, 2008, p. 269.
} 
rastrear lo que en Diferencia y repetición el autor diga sobre la educación o la pedagogía. Tampoco leer en clave pedagógica Diferencia y repetición, ni mucho menos situar un pensamiento pedagógico en la filosofia deleuziana. Creemos que de ahí parten los intentos fallidos al momento de aproximarse al problema de la educación en Deleuze. De lo que se trata, por el contrario, es de tomar algunas de sus ideas/conceptos y desviarlas, proyectarlas en otro terreno, hacerlas hablar en otra lengua, descentrarlas y desarticularlas, en última instancia, de ese lenguaje al que le sirven de base. Esta es, pensamos, la tarea que para Deleuze es propia del pensador y que refleja muy bien su manera de "hacer filosofia". En el trascurso de este artículo nos encontraremos al inicio con las ideas principales de Diferencia y repetición. Tomamos para ello como recurso heurístico de interpretación algunos ejemplos tomados del filósofo y esteta Étienne Souriau, con la finalidad de proyectar y situar funcionalmente los conceptos deleuzianos en la práctica del arte y comprender las categorias de situación interrogante, repetición dinámica y aprendizaje como complementarias o correlativas. Finalmente, confrontaremos dos figuras que ponen en tensión la discusión sobre tiranía o emancipación en la enseñanza: el maestro-tirano (Sócrates) versus el maestro-emancipador (Jacotot-Deleuze).

\section{El teatro de la repetición vs. el teatro de la representación.}

Étienne Souriau, filósofo, esteta y profesor de toda una generación a la que Deleuze perteneció, resume en uno de sus textos tardíos, Del modo de existencia de la obra por hacer (1955), presentado a modo de conferencia, los puntos cardinales de su filosofia que muy bien podría llamarse de lo "virtual" o de la "instauración". Es notorio encontrar allí las afinidades y los entrecruzamientos conceptuales con el autor de Diferencia y Repetición. De hecho, poco se ha escrito sobre esa relación o familiaridad ${ }^{7}$. Creemos oportuno retomar algunas ideas de Souriau para exponer de manera clara y sencilla los conceptos de diferencia y repetición.

De esta forma, en aquella conferencia Souriau recrea, en un deleitante intento por mostrar el proceso dramático, y en ocasiones trágico, al que se ve sometido un artista en la instauración de su obra de arte, el escenario existencial

\footnotetext{
7 La filósofa I. Stengers y el filósofo B. Latour reconocen la deuda "evidente" que Deleuze tiene con Souriau a pesar de que nunca lo nombre. Esta deuda se escabulle a lo largo de su filosofia, siendo la idea de lo virtual la más sonsacada y desarrollada en Diferencia y repetición. Cf., Stengers, I. y B. Latour, "La esfinge de la obra", en: Souriau, E., Los diferentes modos de existencia, Buenos Aires: Cactus, 2017, pp. 7-92.
} 
de la obra de arte por hacer. Pensándose en el lugar del creador de la obra, Souriau deja de lado todo causalismo e idealismo: "La obra por hacer -dice el esteta- jamás nos dice: esto es lo que soy, esto es lo que debo ser, modelo que no tienes más que copiar. Diálogo mudo en el que la obra, enigmática, casi irónica, parece decir: ¿y ahora qué vas a hacer? ¿Mediante qué acción vas a promoverme o a deteriorarme?"8.

La idea de una obra de arte no pre-existe a la obra, no es simplemente el fiel reflejo que va del modelo a la copia, de la esencia a la apariencia. Antes bien, lo que le preocupa a Souriau es que se pierde la dramatización que implica la instauración y creación de la obra. Esta grita a cada instante, a cada pincelada, a cada martillazo del cincel del artista: "adivina, o serás devorado". Habría que considerar, más bien, que la instauración de la obra obedece a otra dinámica, a otro orden de repetición que no es la mera causalidad o conformidad a fin (Kant), bajo leyes ya establecidas que predicen el surgimiento de esta novela o de aquella escultura, por ejemplo. Existe, antes que nada, una "situación interrogante" cada instante que moviliza el cierre de la brecha entre creación y existencia completa de la obra: "Escuchemos el monólogo interior del pintor -dice Souriau-, que es en realidad un diálogo: 'Esta esquina de mi cuadro sigue estando un poco apagada, haría falta aquí un toque vivo, un destello de color. ¿Un azul intenso? ¿Un toque anaranjado?... Aquí una región está insuficientemente llena; ¿pondré un personaje? ¿Un detalle de paisaje? ¿O puedo, por el contrario, suprimir estos personajes que hay aquí, de manera que resalte mejor el oscuro espacio ambiente?'. Lo mismo el literato: 'Aquí me haría falta un epíteto extraño, raro, o inesperado... Allá un sustantivo que resuene con ecos profundos e íntimos... Después de lo que acaba de decir mi personaje, en la boca del otro hace falta una réplica capaz de operar un vuelco dramático"' 10 .

En el proceso de la instauración se define todo. Y este proceso anafórico, como lo llama Souriau, responde a una situación inquietante, dramática, interrogante, que no sigue un plan previsto, ni imita algo, sino que concretiza a través de problemas. El hilo de Ariadna que lleva a la realización completa de la obra no se fundamenta en la representación ni en el concepto. No hay algo como la idea completa del pintor acerca del cuadro, sino tan solo la evolución del gesto: drama abierto por el creador que escenifica un espacio, que pone en movimiento afectos e intensidades, un tiempo propio dado por el ritmo de su

8 Souriau, E., Los diferentes modos de existencia, p. 242.

9 Ibid., p. 238.

${ }_{10}$ Ibid., p. 242. 
trabajo y de la confrontación con su obra. No obstante, esto se logra gracias a que la instauración de la obra obedece a una repetición libre del concepto, una repetición distinta de la causal; es en este punto donde tocamos el centro y el problema de la repetición.

Dos son los órdenes de la repetición: el conceptual y el dinámico. E1 primero generaliza casos, establece leyes conforme a repeticiones causales, y predice. Aquí se establece un proceso estático, seguido por diferencias de orden representativo y conceptual. Piénsese en que cada concepto, nombre o idea simple se define sobre la base de una generalización. Cuando hablamos de hombre, árbol, rojo, casa y demás, no contemplamos las diferencias individuales de cada concepto, sino tan solo una idea general, abstracta, el hombre, el árbol. De esta manera, la naturaleza se categoriza de acuerdo a estas ideas generales que buscan asemejar lo que es desemejante: no hay un solo animal que sea el mismo, lo mismo una piedra o una manzana. Sin embargo, el lenguaje y nuestra forma de pensar generalizan según conceptos, y confieren diferencias solo categoriales o de especie.

No obstante, el problema de la repetición y la diferencia en la filosofia de Deleuze es precisamente otro: "Nuestro problema se refiere a la esencia de la repetición. Se trata de saber por qué la repetición no se deja explicar por la forma de identidad en el concepto o en la representación- en qué sentido reclama un principio "positivo"superior"11. En oposición a gran parte de la filosofia occidental -en contra de lo que podría llamarse la filosofia de la diferencia desde Aristóteles hasta Hegel, cuya tarea es encausar la repetición como diferencia conceptual, bajo la idea de lo Mismo en la representación-, Deleuze toma otro camino, más cercano a Nietzsche, que trata de develar un tipo de repetición dinámica y de una diferencia que no es exterior (conceptual), sino interior.

¿Cómo anular la representación si pareciera que nos ata, que nos constituye? Una primera forma está del lado del acto de creación artística en donde, como afirma Souriau con respecto a la obra por hacer, siempre hay un encuentro con lo diferente; nada está predispuesto, sino que la obra se constituye siempre como interrogante con encuentros puramente diferenciales. La imitación no es el propósito del artista y del arte, como pensaba Aristóteles, sino la superación del juego, de la dinámica propia de un proceso, del logro de no escuchar la voz misteriosa que dice: “¡Harold, te equivocaste!”12; de lo contrario, se vuelve a empezar y a dinamizar con un nuevo espacio, con nuevos gestos e intensi-

11 Deleuze, G., Diferencia y repetición, Buenos Aires: Amorrortu, 2002, p. 47.

12 Souriau, E., Los diferentes modos de existencia, p. 237. 
dades. De ahí que, para Deleuze, exista una diferencia interna no conceptual, y que "en el orden dinámico, ya no [haya] ni concepto representativo, ni figura representada en un espacio preexistente. Hay [más bien] una Idea y un puro dinamismo creador del espacio correspondiente"13. Este otro orden repetitivo, el dinámico, constituiría otra forma de causalidad, una causalidad actuante, donde lo importante es la repetición de una diferencia. Es notoria la técnica de Van Gogh, por ejemplo, en su cuadro la Carretera con ciprés bajo el cielo estrellado, que induce a pensar que cada pincelada es única, original, a diferencia de un cuadro de Tiziano o Caravaggio, donde la pincelada es un fluir continuo con un mismo tono. Lo que hace Van Gogh es precisamente crear un espacio diferencial, cada plumazo, cada comilla es una diferencia en sí, un tono y un color único; de esto resulta el espacio estrellado, del que tanto gustaba pintar.

Hay, además, otra forma de anular la representación, y tiene que ver nuevamente con una repetición que es dinámica. A modo de ilustración, escuchemos estas descripciones de Proust, desde el rincón de su alcoba: "Según que sea más o menos claro este débil rayo por encima de las cortinas, me indica el tiempo que hace, e incluso antes de decírmelo me señala su tono, pero ni siquiera lo necesito. Vuelvo todavía contra la pared y antes incluso de que haya aparecido, por el sonido del primer tranvía que se acerca y por su campañilla, puedo afirmar si rueda con resignación hacia el azur... los primeros ruidos de la calle me traen el tedio de la lluvia en donde se hielan, la luz del aire gélido en donde vibran, el descenso de la niebla que los apaga, la suavidad y las bocanadas de un día tempestuoso y tibio, en donde el leve aguacero apenas los moja"14.

Esta descripción de impresiones muestra que en el orden del hábito y de las repeticiones cotidianas, es posible sonsacar diferencias que indican un estado de cosas. Habría, así, un orden que precede a toda representación, y es un orden de síntesis pasivas que no son más que hábitos. Pero, a su vez, estos constituyen signos que determinan un tiempo y la propia acción. La luz en la ventana, por ejemplo, indica que ya es hora de levantarse. El campaneo del reloj indica que ya son las doce. Cada una de estas repeticiones-hábitos se contraen en el espíritu que las contempla, pero de manera pasiva, no activa, es decir, no las representamos, simplemente ellas nos constituyen, habitan en cada parte de nuestro cuerpo, y dirigen los procesos orgánicos, dentro de ellos nuestra propia acción de pensar. De ahí la tesis de Deleuze: "[La síntesis pasiva] no está hecha por el espíritu, sino que se hace en el espíritu que la

${ }^{13}$ Deleuze, G., Diferencia y repetición, p. 49.

${ }^{14}$ Proust, M., La muerte de las catedrales, Bogotá: Norma, 1993, pp. 31-32. 
contempla, precediendo toda memoria y reflexión"15. Dicho en otras palabras, para Deleuze nosotros no constituimos un mundo: son el mundo y nuestros hábitos más que nada, los que nos constituyen, los que nos guian, los que nos hacen. No hay un "yo" constituyente, sino un yo en constante modificación.

Esta forma de anular -y cabría más bien decir de posibilitar- la representación le sirve a Deleuze para mostrar, en primer lugar, que existe un campo pre-subjetivo y pre-representativo constituido por una dinámica intensiva de orden repetitivo. Cada parte del cuerpo, cada órgano de los sentidos, es una placa sensible que contrae (o contempla) impresiones de acuerdo a ciertos ritmos y diferencias intensivas. Un animal se forja un gran oído gracias a la repetición de sonidos privilegiados, pero también porque logra sonsacar diferencias de nivel en los tonos. Un mismo sonido no forja un buen oído, cada placa sensible (órgano) debe contraer un cúmulo de diferencias auditivas para permitir la percepción. De esto también se desprende que el propio oído debe ser antes que nada sonido, es decir, debe constituirse en su propio ser de vibraciones, es oído, pero también vibración, sonido, música. Así Deleuze nos dice que "[e]n el orden de la pasividad constituyente, las sintesis perceptivas remiten a síntesis orgánicas, así como la sensibilidad de los sentidos, a una sensibilidad primaria que somos. Somos agua, tierra, luz y aire contraídos, no solo antes de reconocerlos o representarlos, sino antes de sentirlos. Todo organismo es, en sus elementos receptivos y perceptivos, pero también en sus vísceras, una suma de retenciones, contracciones y esperas"16.

En el acto de contraer y retener a través de ritmos e intensidades se instituye la dimensión temporal. Cada repetición de instantes supone un presente viviente, donde el pasado representa lo que ya ha sido impreso, repetido o convertido en hábito. Se recuerda lo que ya ha sido puesto, modelado o impreso en los sentidos; se tiene el recuerdo de una experiencia vivida, de otro modo, no se tendría noción de algo pasado. El futuro sería la anticipación de una repetición, de una contracción. Cuando se tiene hambre se quiere satisfacer una contracción que ya ha estado impresa; así, el futuro se instituye en un querer contraer de nuevo lo que ya está impreso, de modo que el tiempo en la repetición es un retener (pasado) y un satisfacer (futuro) en un presente vivo.

Todo lo dicho hasta aquí lo retomo para acentuar el carácter pre-subjetivo y pre-representativo que condiciona a todo individuo. El sujeto activo supone uno pasivo que lo implica, lo envuelve y lo modifica. La tesis de Deleuze va más

15 Deleuze, G., Diferencia y repetición, p. 120.

16 Ibid., p. 123. 
allá: "[b]ajo el yo que actúa, hay pequeños yo que contemplan y que vuelven posible la acción y el sujeto activo. No decimos "yo"más que por mil testigos que contemplan en nosotros; es siempre un tercero el que dice yo" ${ }^{17}$. La famosa síntesis activa olvida su otra síntesis, la pasiva, y el tránsito de esta en aquella será la clave para comprender la dinámica del aprendizaje y la conformación de la subjetividad.

Ahora bien, estos dos aspectos que posibilitan la re-presentación y que son una salida o anulación a su dominio conceptual, trazan el camino que finalmente Deleuze pretende surcar, a saber, un método de dramatización en oposición al método de generalización, propio de la imitación y representación. En aquel método se dramatizan Ideas, no se representan conceptos.

Llegados hasta aquí podemos decir que en la idea de repetición dinámica se cifran las claves del aprendizaje. La representación unida a la acción solo supone un encuentro con lo Mismo, como lo diferente que hay entre conceptos y categorias. Antes que ser un móvil para la acción y el aprendizaje de nuevas cosas, la representación termina siendo un obstáculo y una imposición de leyes, un seguimiento de patrones. Lo mismo sucede con la imitación, al ser solo re-producción de casos iguales no fuerza al cuerpo y al espíritu a un encuentro original con la diferencia. No hay una creación dinámica de un espacio propio, no hay una situación problemática.

\section{2. ¡Dramatizad Ideas!: en busca del método de dramatización}

En su cuaderno de apuntes, Nathaniel Hawthorne (1804-1864), escritor y uno de los más destacados autores del romanticismo oscuro y del gótico norteamericano, escribe ideas desordenadas, frases sueltas y breves esbozos que más adelante se traducirán en relatos, cuentos o novelas. Detallemos algunas: "Hacer de la propia imagen en un espejo el tema para un cuento"18; "Una hoja suelta del Libro del Destino. Alguien la recoge en la calle"19; "Un indagador que busca el Pecado Imperdonable. Al fin lo encuentra en su propio corazón y en sus obras" 20 . Muchas de estas ideas son intrigantes, oscuras, producen ciertos afectos confusos, pero, sobre todo, dejan a la imaginación su posible desenlace, las diversas articulaciones que podrían tener en una narración completa o los diversos caminos o vericuetos que podría encarnar este o aquel personaje,

17 Ibid., p. 127.

18 Hawthorne, N., Cuaderno de apuntes, Bogotá: Norma, 1990, p. 29.

19 Ibid., p. 37.

20 Ibid., p. 37. 
etcétera. Lo cierto es que estas ideas tienen un tipo de existencia virtual, y para que sean sacadas por completo a la luz de la existencia narrativa, poética, escultórica, etcétera., es necesario un proceso de intensificación o actualización. ¿Cómo pasan de un tipo de existencia virtual a uno actual? ¿Qué papel tienen la idea de repetición y diferencia en este proceso de intensificación?

Es importante como primera medida, precisar qué es un virtual. David Lapoujade describe este tipo de existencia, a la luz de su lectura de la filosofia de Etiénne Souriau, como eso que está ahí, “alrededor nuestro, aparecen, desaparecen, se transforman a medida que la realidad misma cambia; no tienen ninguna solidez, ningún cimiento, ninguna consistencia. En ciertos aspectos, es el universo más vasto y más rico, al menos en apariencia, pero es también el más evanescente, el más inconsistente, el más cercano a la nada"21.

Un virtual puede aparecer, por ejemplo, cuando vemos el esbozo de un puente recién empezado, y nosotros mismos determinamos o anticipamos virtualmente su completitud. Un camino embadurnado de lodo puede tener piedras aisladas, pero también es cierto que podemos tomarlas virtualmente para imaginar un camino: "[r]estos de conversación devienen germen de un relato, los rasgos de un rostro se transforman en retrato eventual, algunas notas forman el comienzo de una melodía, un guion se convierte en film, una intuición en sistema, etcétera. No hay realidad que no esté acompañada de una nube de potencialidades que la sigue como su sombra"22.

Desde el acto más íntimo de nuestra experiencia individual, de nuestra vida psíquica, hasta el aspecto más complejo de las ideas artísticas o incluso científicas, los virtuales abundan, pero como bien lo ve Lapoujade, su existencia es evanescente. Lo que no se toma en cuenta es que estos virtuales tienen el poder de cambiar e influir en la realidad: qué sería del mundo, por ejemplo, sin las maravillosas obras de arte dispuestas alrededor del mundo o sin los dispositivos tecnológicos que interpelan nuestras vidas. Cada obra concreta es un virtual actualizado, potenciado por los más profundos afectos e intensidades, dispuestos en un campo espacio-temporal definido no por la imitación directa de la presencia de ese virtual, sino, muy al contrario, por un drama existente en la tarea de aproximarlos a la frontera de lo real. En otras palabras, los virtuales se actualizan gracias a los espacios dramáticos e inquietantes de una repetición dinámica.

21 Lapoujade, D., Las existencias menores, Buenos Aires: Cactus, 2017, p. 32.
22 Ibid., pp. 32-33.

ARETÉ Revista de Filosofía, v. XXXIII, 1, 2021 / e-ISSN 2223-3741 
Es aquí donde Deleuze ilumina ese tránsito de lo virtual a lo actual, pues al delimitar bien esos dos campos, el de lo virtual como dominio de la Idea, y lo actual como el dominio de las cualidades y extensiones, especies y partes ya constituidas, pone a la diferencia de intensidad como elemento genético de ese tránsito: "La actualización de lo virtual -nos dice- siempre se hace por diferencia, divergencia o diferenciación [différenciation] ${ }^{23}$. La actualización rompe tanto con la semejanza como proceso, como con la identidad como principio. Nunca los términos actuales se asemejan a la virtualidad que actualizan; las cualidades y las especies no se parecen a las relaciones diferenciales que encarnan; tampoco a las partes que encarnan. En ese sentido, la actualización, la diferenciación siempre son una verdadera creación"24.

No hay imitación ni una correspondencia de los elementos virtuales con los actuales, todo se da en el proceso de repetición dinámica, donde lo que se pone en juego es la creación de un espacio y un tiempo propios, dados por las diferencias de intensidad o por una gama de afecciones. El orden conceptual o representativo no tiene como tarea dramatizar o mostrar los dinamismos diferenciales, sino solo generalizar casos a partir de diferencias extensivas, es decir, de orden también conceptual. Este es quizás el punto que más le incomoda a Deleuze, y es precisamente la incapacidad del concepto para determinar un espacio y tiempos propios, para dramatizar Ideas. Kant ya había tratado de acercarse a esta noción al postular las Ideas regulativas de la razón, mas solo para relegarlas a una indeterminación objetiva, sin correlato empírico y conceptual. Deleuze ve una fisura en este modo de postular las Ideas y piensa que es en esta carencia donde la diferencia puede actualizar cualquier Idea. Como bien lo expresa Pardo: "[hay] intuiciones que no se adecuan a ningún concepto [Ideas según Kant], para las cuales es preciso inventar un concepto, una "idea estética" que exprese lo que de inexpresable hay en una idea racional, su diferencia" 25 . ¿No es acaso este el trabajo del arte, esto es, mostrar fuerzas irrepresentables? ¿No es trabajo del arte pintar, contar, dramatizar intensidades, espacios diferenciales irreductibles al concepto?

Es importante ahora mostrar que en esta dinámica intensiva y repetitiva que permite actualizar lo virtual, se cifran las claves de una nueva ontología,

\footnotetext{
${ }^{23}$ Deleuze hace una distinción entre diferentiar (con $t$ ) y diferenciar (con c) para delimitar los campos de lo virtual y lo actual respectivamente: "Llamamos diferentiación a la determinación del contenido virtual de la Idea; hemos llamado diferenciación a la actualización de esa virtualidad en especies y partes distinguidas" (Deleuze, G., Diferencia y repetición, pp. 311-312).

${ }^{24}$ Deleuze, G., Diferencia y repetición, p. 319.

${ }^{25}$ Pardo, J. L., A propósito de Deleuze, Valencia: Pre-textos, 2014, p. 78
} 
a saber, la que se encuentra en Diferencia y repetición. Lo que impera en esta nueva ontología es "lo que actúa [en los individuos constituidos] como principio trascendente, como principio plástico, anárquico y nómade, contemporáneo del proceso de individuación, no menos capaz de disolver y destruir los individuos que de constituirlos temporariamente: modalidades intrinsecas del ser, que pasan de un 'individuo' a otro, que circulan y se comunican bajo las formas $y$ las materias" 26 .

Lo que intenta mostrar Deleuze, como variante a las diversas ontologias desde Aristóteles hasta Heidegger, son los efectos profundos que encubre el ser o todo individuo constituido, o, dicho en otras palabras, todo el caos que encierra un cosmos (animal o sujeto) ya individualizado. Esos efectos de profundidad son los que ya hemos mostrado: la repetición dinámica, la diferencia intensiva que le subyace y el dominio de la Idea o, lo que es lo mismo, lo virtual. Estos son los principios genéticos que anteceden a toda estructura ya formada en partes y extensiones. Los principios nómades corresponden, así, a una dinámica puramente intensiva y cualitativa, antes que extensiva y cuantitativa. El resultado será una teoría de la individuación cuyo principio encarna la diferenciación: "La diferencia no es lo diverso. Lo diverso es dado. Pero la diferencia es aquello por lo que lo dado es dado como... diverso... Todo fenómeno remite a una desigualdad que lo condiciona. Toda diversidad, todo cambio remiten a una diferencia que es su razón suficiente. Todo lo que pasa y aparece es correlativo de órdenes de diferencias, diferencias de nivel, de temperatura, de presión, de tensión, de potencial, diferencia de intensidad"27.

Ahora bien, ¿cómo se articula todo esto con una idea de aprendizaje? ¿Cómo pensar, a partir de lo que hemos dicho, una pedagogía de la diferencia en la filosofia de Gilles Deleuze? Partamos de la diferencia nuevamente entre un concepto y una Idea. El concepto, como se mostró al inicio, está determinado por los elementos de la especificación y organización en los cuales la diferencia es tan solo exterior: procede diferenciando categorias, especies y órdenes de semejanza. La Idea, muy al contrario, procede bajo relaciones diferenciales y distribución de singularidades, crea un espacio y un tiempo propios, así como intensidades dinámicas y diversos órdenes de repetición actuante. Se diría, incluso, que el concepto es abstracto, mientras que la Idea no es abstracta, sino virtual, tiene otro tipo de realidad que no está determinada ya de antemano, sino que adquiere concreción en el proceso de actualización. En palabras de

${ }^{26}$ Deleuze, G., Diferencia y repetición, pp. 75-76. Énfasis nuestro.

27 Ibid., p. 333. 
Deleuze, "la Idea es una imagen sin parecido; lo virtual no se actualiza por semejanza, sino por divergencia y diferenciación”28.

En este sentido, el concepto no forzaría a un encuentro propio, dinámico y actuante con lo diferente o con lo Otro, pues tan solo sería un movimiento o encuentro entre puros conceptos. Mientras que, por otro lado, la Idea moviliza una dinámica propia y actuante, el individuo es quien crea un espacio de comunicación entre su Idea, que es virtual, y su actualización. Él mismo es quien a través de su cuerpo y de su espíritu libera intensidades y afecciones, ritmos y velocidades. Para ilustrar esto tomemos un ejemplo del propio Deleuze. Para aprender a nadar hay dos caminos: o bien reproduciendo en la arena o en el suelo los movimientos que el maestro proporciona, o, al contrario, enfrentándose de una vez al agua, tratando de dinamizar con ese espacio. Si se sigue la primera, no se aprende, solo se reproduce lo Mismo; hay una dinámica estática, imitativa, sin creación de un espacio y un ritmo. Por el contrario, siguiendo la segunda manera, hay un enfrentamiento y disposición de comunicación entre el movimiento de las olas y la dinámica propia del cuerpo, se abre así un espacio intensivo, se siente el movimiento, el agua, y el ritmo de las olas de la misma manera que el cuerpo y sus propias afecciones se entremezclan. En palabras de Deleuze: "No aprendemos nada con aquel que nos dice: 'haz como yo'. Nuestros únicos maestros son aquellos que nos dicen: 'haz junto conmigo', y que, en lugar de proponernos gestos que debemos reproducir, supieron emitir signos susceptibles de desarrollarse en lo heterogéneo... Cuando el cuerpo conjuga sus puntos notables con los de la ola, anuda el principio de una repetición que ya no es la de lo Mismo, sino que comprende la diferencia, de una ola y de un gesto al otro, y que transporta esta diferencia en el espacio repetitivo así constituido"29.

¿Qué implicaciones tendría una pedagogía libre de las ideas de imitación y representación conceptual? ¿Qué significaría crear un espacio de comunicación heterogéneo, donde el maestro fuerce al educando a desarrollar y construir su propio espacio intensivo, poniendo, así, a trabajar su propia inteligencia y no la de él, su maestro? ¿Qué implicaciones éticas y políticas tendría una pedagogía de la diferencia?

\footnotetext{
${ }^{28}$ Deleuze, G., La isla desierta y otros textos: textos y entrevistas (1953-1974), Valencia: Pretextos, 2005, p. 135.

${ }^{29}$ Deleuze, G., Diferencia y repetición, pp. 52-53.
} 
3. ¿Preguntar para instruir o para ser instruido?: sobre la pedagogía de la imitación y el método socrático

Es preciso comprender el "haz junto conmigo" al que se refiere Deleuze, pues es allí donde se encuentra la relación que subordina, por un lado, el aprendizaje, bien sea a la idea de lo mismo o a la de lo diferente, así como también la manifestación libre de la inteligencia del educando, bien sea a su propia capacidad o a la supresión de esta por la instrucción del maestro, por otro. Partamos del "haz como yo", lema clásico de la enseñanza y de las ideas de formación que impregnan la práctica pedagógica. Es bajo esta idea que se encarna la lógica de lo mismo o del orden conceptual, de una finalidad y causalidad que es preciso transmitir, comunicar al estudiante para llevarlo a un estadio superior en la escala del conocimiento y de su humanidad, convertirlo en hombre. Este ideal fue el que prevaleció en la cultura griega: lo propio de la paideia era "formar... verdaderos hombres, del mismo modo que el alfarero modela su arcilla y el escultor sus piedras, es una idea osada y creadora que solo podía madurar en el espíritu de aquel pueblo artista y pensador" 30 . La efigie del maestro que se desprende de este modelo de educación termina siendo la de aquel que somete al estudiante a sus propios intereses, es el que dirige la marcha, surca sus propios caminos hacia una idea que él ha preconcebido de antemano, fuerza la acción del niño o del estudiante en pro de sus propios designios. En todo el recorrido de la "enseñanza" del maestro, no aparecen vestigios de la manifestación de la voluntad e inteligencia del estudiante: este es solo un medio, un instrumento que es necesario se deje moldear, domesticar, dominar y someter. De esta manera, la práctica pedagógica del maestro, que se funda en una lógica teleológica, propia del orden representativo e imitativo, se convierte en una práctica de la dominación y la desigualdad. El teatro de la representación pasa a ser, en la práctica educativa, un teatro de marionetas.

Quizá se ha considerado el método socrático como el modelo por excelencia del saber y la enseñanza, el método dialéctico que busca en los recovecos del alma de cualquiera la semilla de un saber que antes ignoraba y que ahora, gracias al que pregunta, sale a la luz. Sin embargo, es necesario reconsiderar la relación que se instaura entre el maestro Sócrates y cualquiera de sus interlocutores, pues es allí, en la relación pregunta-respuesta, donde es posible reconocer si se dan relaciones de dominación y subordinación de la inteligencia

\footnotetext{
${ }^{30}$ Jaeger, W., Paideia: los ideales de la cultura griega, México, D. F.: Fondo de Cultura Económica, 1995, pp. 10-11.
} 
o, por el contrario, de liberación de ella en cualquiera -y con ello la auténtica muestra de un saber no transmitido. Qué es lo que se busca con la pregunta, y más aún, quién es el que busca y quién es el que encuentra la respuesta, son algunas preguntas para distinguir al maestro-tirano del maestro-liberador de la inteligencia.

Es sabido que, en el Menón, Sócrates pretende dilucidar la cuestión de si es posible o no enseñar la virtud. Gracias a un procedimiento preguntarespuesta, Sócrates lleva al esclavo de Menón a descifrar algunas verdades geométricas, relacionadas con las justas proporciones, mostrándole que la medida de su saber, la del esclavo, está en él. No obstante, el diálogo toma otro rumbo cuando este no acierta una pregunta. Sócrates ahora se propone demostrarle su error haciéndolo nuevamente errar. Pero es precisamente allí, en mostrarle su error y en entorpecerlo, donde Sócrates cree mostrarle su saber: "Sóc. -Te das cuenta una vez más Menón, ¿en qué punto se encuentra ya del camino de la reminiscencia? Porque al principio no sabía cuál era la línea de la superficie de ocho pies, como tampoco ahora lo sabe aún; sin embargo, creía entonces saberlo y respondía con la seguridad propia del que sabe... Men. -Es verdad. -Sóc. -¿Entonces está en una mejor situación con respecto al asunto que no sabía? -Men. -Así me parece. -Sóc. -Al problematizarlo y entorpecerlo, como hace el pez torpedo, ¿̇le hicimos algún daño? -Men. -A mí me parece que no. -Sóc. -Le hemos hecho, al contrario, un beneficio para resolver cómo es la cuestión... ¿Crees acaso que él hubiera tratado de buscar y aprender esto que creía que sabía, pero ignoraba, antes de verse problematizado y convencido de no saber, y de sentir el deseo de saber? -Men. -Me parece que no, Sócrates. -Sóc. - ¿Ha ganado, entonces, al verse entorpecido? -Men. -Me parece" ${ }^{\prime 1}$.

Retomemos las preguntas: ¿quién es el que busca y quién es el que encuentra? Nos parece que es el propio esclavo quien busca y encuentra, pero, en realidad, es Sócrates el domador de la mente del esclavo, es él quien busca sacar una verdad a través de este. Y, ¿qué es lo que busca? Mostrarle la medida de su error, la medida de su incapacidad e incompetencia para comprender problemas, solo así le demuestra Sócrates que no tiene la verdad, y que es necesario hacerlo errar, entorpecerlo, como él lo dice, para que reaccione, para que ahora sí quiera ir a la búsqueda de un saber. En otras palabras, Sócrates le demuestra al esclavo que él por sí mismo es incapaz de salir de su condición si antes no ha sido entorpecido, si antes no se le ha mostrado que es incapaz

31 Platón, Menón, 84b-84d. 
de salir de un problema, y también, si no es con la ayuda de un maestro. A diferencia de toda una tradición que veía en la figura de Sócrates al hombre virtuoso y en la dialéctica el método de la razón, Nietzsche no se equivocaba al decir, aludiendo a Sócrates, que "[s]i uno es dialéctico tiene en la mano un instrumento impecable; con él puede hacer el papel de tirano; compromete a los demás al vencerlos. El dialéctico deja a su adversario la tarea de probar que no es un idiota: hace rabiar a los demás, y al mismo tiempo los deja desamparados. El dialéctico vuelve impotente el intelecto de su adversario"32.

De esa impotencia Sócrates saca provecho. De antemano él ya sabe las respuestas, siempre está un paso más allá del esclavo, nunca hay un punto en el que los dos salgan, conjuntamente, de un problema. Se anticipa a las respuestas, da otro paso y anuncia la siguiente, $\mathrm{y}$, finalmente, es momento para sacar un as bajo la manga: la pregunta dificil que él sabe que el esclavo no podrá responder. El maestro siempre está por delante del estudiante, siempre detenta un saber que es preciso transmitir y que el estudiante pasivamente, impotentemente, sabrá recibir y acumular. No hay más salidas; el estudiante sabe que el maestro es el único que puede dirigirlo.

Hay toda una finalidad en el camino de "enseñanza" de Sócrates. La lógica de lo Mismo lo obliga a moverse entre una dinámica puramente conceptual, necesaria para consumar la meta prevista desde el inicio del diálogo: inteligir y transmitir una Idea. Pero es sabido que esta tarea llega a su realización abstractamente, y con esto quiero decir que es solo Sócrates el director del teatro. El esclavo de Menón no actúa bajo su propia inteligencia, no dinamiza con la Idea que quiere transmitir el maestro, solo sigue los pasos casi ciegamente, de alli el embotamiento, los momentos de incomprensión de la mayoría de los interlocutores en los diálogos. El esclavo es obligado a seguir la marcha abstracta de su maestro, el "haz como yo" al que se refiere Deleuze.

Quizá ha sido en términos actuales Jacques Rancière quien más ha problematizado el método socrático a través de otro educador, Joseph Jacotot, que encarna justamente la figura antitética de ese método. Rancière sintetiza todo lo dicho hasta aquí, aludiendo a una elocuente ilustración del método del maestro-tirano dada por Jacotot: "El método socrático de la interrogación que pretende conducir al alumno a su propio saber es, de hecho, el de un domador de caballos: 'Dirige las revoluciones, las marchas y contramarchas. En lo que a él respecta, tiene la serenidad y la dignidad de quien controla la doma de la

${ }^{32}$ Nietzsche, F., El crepúsculo de los ídolos, Madrid: Alianza Editorial, 1971, p. 43. 
mente que dirige. De jinetada en jinetada, la mente llega a una meta que no había siquiera vislumbrado en el punto de partida. Se asombra de alcanzarla, se da vuelta, ve a su guía, el asombro se vuelve admiración, y esa admiración lo embrutece" 33 .

Ese saberse ausente durante todo el camino de aprendizaje, y el asombro que produce la superioridad intelectual del maestro que ha conducido hasta allí al alumno, es lo que lo embrutece. La lógica de lo Mismo que reproduce esta forma de enseñanza vuelve impotente los cuerpos y su capacidad para crear, imaginar, soñar, sonsacar diferencias, querer expresar Ideas inexpresadas, saberse presente en todos los momentos de su formación, actualizar sus Ideas, y no las del maestro, invocando e instaurando un espacio y un tiempo, dando ritmos intensivos, cual artista delante de su obra. Esto último es el "haz junto conmigo" al que se refiere Deleuze, y que más adelante, en sus trabajos a dueto con Félix Guattari se consolidará bajo el concepto de devenir. Lo propio del alumno no es imitar ni seguir la marcha abstracta del maestro, antes bien, el alumno tendrá que movilizar su inteligencia para solucionar un problema, tendrá que devenir-pintor-poeta-músico-etcétera, para salir del territorio que el maestro ha sabido crear, y para ello no es necesario imitar o verse entorpecido, sino atreverse a expresar las aventuras de su espíritu.

4. ¡Abajo el método, abajo la Imagen del pensamiento! sobre la afirmación de la inteligencia

“[E]1 maestro (en la Enseñanza universal) no posee método; de este modo usted no puede comparar este método con ninguno de los buenos métodos que preside. Es verdad que el alumno (en la Enseñanza universal) posee un método, pero ese método, esa marcha del espíritu humano, esa serie de procedimientos intelectuales no es asible, no se lo puede escribir y depositar en el despacho de la sociedad [de métodos], y usted no es presidente de ese método... [P]ara enseñar la música digo al alumno que toque, improvise, haga un dúo, un trío, un cuarteto, una partitura: él hace todo a través de su método; juzguen el método del alumno, pónganlo en vuestro crisol si ustedes quieren, ¡tan sabios como son!... ¿ ¿es que vuestra sociedad no tendría suficiente espíritu para ver que yo no poseo método que pueda ser examinado, juzgado, alabado, censurado, comparado? Hagan creer a los padres pobres que existe un gran misterio a develar, un profundo análisis que hacer, y que ellos deben esperar respetuosamente

${ }^{33}$ Rancière, J., El maestro ignorante, Buenos Aires: Edhasa, 2018, pp. 102-103. 
que les digan cuándo y cómo podrán permitirse comenzar"34. Esta contestación dirigida a la alta Sociedad de Métodos de Enseñanza, encabezada por el conde de Lasteyrie, quien, estando preocupado y asombrado por la noticia de que pequeños alumnos de la escuela superior de París están escribiendo poemas con mayor fluidez que la de sus profesores, y a la altura incluso que los versos de Racine o Corneille, decide tomar partido y dirigir una carta al ilustre maestro que ha llevado a sus estudiantes a tan alto nivel. Joseph Jacotot no tarda en escribirle aquellas fervientes líneas en respuesta a su conmoción por querer saber el método que él utilizó para instruir a sus estudiantes. La respuesta es tajante: no hay método. El único método es el que cada estudiante emplea y no es posible saber eso, no es posible meterse en la cabeza de cada uno y observar los pasos que ha dado y generalizar un solo camino que les correspondería a todos. El escándalo no se hizo esperar: si no hay método, si no hay un camino a seguir, el edificio de la pedagogía no tiene ya sus cimientos y tambalea. Jamás ha venido a la mente de nadie decir a otro "yo he aprendido muchas cosas sin explicaciones, creo que usted puede hacerlo como yo"35. ¿Qué tiene que hacer el maestro? ¿Qué debe transmitir a sus alumnos? ¿Qué puede explicarles? En cada pregunta se precisa de una forma de enseñanza y de la necesidad de un maestro que conduzca la marcha de los estudiantes, pero Jacotot no cree en eso, no cree que el maestro tenga necesidad de enseñar, es decir de transmitir ideas y llenar espíritus con explicaciones. Pero, ¿cómo llevó a que niños escribieran poemas como los de Racine?

En plena época ilustrada nadie comprende lo que Jacotot quiere mostrar, esto es, que "Todo está en todo" es el lema de la enseñanza universal y el método natural de la inteligencia humana: "Los diarios alemanes [nos dice], que resonaron con lo objetivo y lo cognitivo de Kant, no dicen una palabra de "Todo está en todo" 36 . Pero si lo que dice Jacotot no resuena en los oídos abstraídos e imbuidos de la filosofia de Kant, es hoy momento de escucharlo y traerlo de vuelta, pues el proyecto filosófico de Deleuze, sostengo, no ha tenido otra finalidad que derribar el "haz como yo" que se sostiene en un método ajeno, y superponer un método propio e inmanente a la inteligencia humana, desprovista de toda necesidad de modelos, métodos y explicaciones. Diferencia y repetición es el desarrollo de esta idea, pero es el tercer capítulo, La imagen del pensamiento, el que da la estocada final al asunto. En él, Deleuze combate,

\footnotetext{
${ }^{34}$ Jacotot, D., Enseñanza universal: lengua materna, Buenos Aires: Cactus, 2008, pp. 292-295.

${ }^{35}$ Ibid., p. 289.

${ }^{36}$ Ibid., p. 165.
} 
como lo hizo Jacotot contra la sociedad de métodos, la idea dogmática del pensamiento que invade gran parte de la filosofia: la del "pensamiento como ejercicio natural de una facultad... el presupuesto de un pensamiento natural dotado para lo verdadero, en afinidad con lo verdadero, bajo el doble aspecto de una buena voluntad del pensador y de una recta naturaleza del pensamiento"37. Ya sea bajo la idea de una dialéctica o bajo el modelo de lo claro y distinto, como en Platón y Descartes respectivamente, el pensamiento está subordinado a su encuentro con la verdad. No hay pensamiento si no es buscando la verdad, si no se precisa de un buen camino, de unas buenas proposiciones lógicas, de unas explicaciones claras o de una formalización bajo conceptos. Esta es la buena voluntad del pensador. Todo aquel que quiera atreverse a pensar tiene que hacerlo bajo esta Imagen dogmática o régimen representativo.

Como es de esperarse, Deleuze rompe con esta Imagen a través de la diferencia intensiva. Si la Imagen se sirve de métodos, conceptos y de la representación para seguir en pie, lo que fuerza a pensar debe estar del lado, por el contrario, de lo sentido, de las diferencias intensivas y de la gama de afectos que mueven la acción. Para querer reproducir la tesitura de una nota, por ejemplo, cuyo sonido estridente retumbe el escenario, se necesita buscar una nota particular cuya diferencia sonora sea sentida por el músico y conducida al pensamiento para que decida bajo qué umbrales la reproducirá. O cuando el poeta quiere en la ligereza de un verso expresar un sentimiento, necesita traducir los afectos e imágenes impresas en su espíritu en palabras acomodadas por el pensamiento. En cada caso problemático se trata de conducir una diferencia sentida que fuerce el pensamiento a decidir o actuar. Desde las experiencias más simples hasta las más complejas vemos cómo la inteligencia remite a un fondo diferencial, a un acuerdo discordante entre lo sentido y lo representado. La inteligencia no se queda únicamente del lado de la representación, de la memoria, o de la adecuada producción de proposiciones o silogismos, como quiere la Imagen dogmática, sino que "siempre es por una intensidad que adviene el pensamiento"38.

De todo esto se desprende la misma consecuencia que reclama Jacotot: no hay método para volver inteligentes a los alumnos. "Nunca se sabe por anticipado [nos dice Deleuze] cómo alguien va a aprender: por qué amores se llega a ser bueno en latín, por qué encuentros se es filósofo, en qué diccionarios se

${ }^{37}$ Deleuze, G., Diferencia y repetición, p. 204.

${ }^{38}$ Ibid., p. 215.

ARETÉ Revista de Filosofia, v. XXXIII, 1, 2021 / e-ISSN 2223-3741 
aprende a pensar"39. El asunto de la inteligencia y del aprendizaje tiene que ver más con una búsqueda y un encuentro que deviene intensivo para el pensamiento, que con una imitación de modelos y conceptos. Por ello, cada estudiante es el que conduce su propia inteligencia, es él quien está a la búsqueda de encuentros que lo fracturen y lo violenten para sonsacar diferencias. El aprender está siempre al acecho, es el movimiento natural de la inteligencia, en cualquier lugar y bajo cualquier circunstancia se está al encuentro de una situación problemática: el carpintero que necesita dar forma a la madera para hacer encajar partes de diferente amplitud tiene que tocar la madera, imaginar los contornos, repetir, intentar, volver a empezar; todo se convierte en una búsqueda. No hay molde que copiar, sino un camino a superar movilizado por diferencias de orden no-conceptual y repeticiones dinámicas. De ahí la consecuencia de Deleuze: "el aprender es la verdadera estructura trascendental"40.

Puesta esta estructura trascendental en su sitio, esto es, del lado inmanente de la inteligencia y de la propia naturaleza humana, y ya no, por el contrario, del lado del método, se comprende el lema de la Enseñanza universal de Jacotot. Es universal porque está en todos, es inmanente, y, por tanto, abre paso a la igualdad de las inteligencias. Tal vez "nosotros no tenemos todos los mismos gustos [dice Jacotot], las mismas disposiciones, es decir, la misma voluntad; pero el niño más pequeño posee la misma inteligencia que Arquímedes adulto"41. He aquí lo paradójico de querer nombrar y comparar el método de la enseñanza universal: desde que se comienza a vivir, no hay nadie que no haya aprendido por su propia cuenta un montón de cosas, que no haya imitado, repetido y experimentado diferencias intensivas, que no se haya sumergido en las olas. Eso es lo que reclama Jacotot a la sociedad de métodos y Deleuze al tribunal de la razón filosófica: "el método no es nada"42 dice Jacotot por su lado, y "no hay método para encontrar los tesoros"43 dice Deleuze, por el suyo.

De esta manera, si sus reflexiones parten de una crítica epistemológica a modelos establecidos de enseñanza y pensamiento, no es casualidad que terminen en reflexiones ontológicas y políticas. Pues lo que ponen en cuestión es el hecho de que cada institución necesita partir del presupuesto contrario al de la igualdad de las inteligencias: el de una voluntad de buen pensador y 
del maestro sabio explicador. "Hagan creer a los padres pobres que existe un gran misterio a develar" 44 le replica Jacotot al presidente de la sociedad, como denuncia a la creencia de que existen personas aparte, dotados intelectualmente para instruir al pueblo. Con esto la sociedad de métodos gana la alienación de los padres: estos se convencen de que es imposible enseñarle algo a sus hijos si no es con la ayuda de un maestro que les explique los misterios de la gramática, la aritmética o la poesía. Pero lo cierto es que no hay misterios, no hay un velo, no hay apariencias, estos son recubrimientos retóricos para mantener la fe en la desigualdad: "el hombre se ha creado una infinidad de necesidades ficticias que observa como necesarias. Las explicaciones orales son de ese tipo"45. Así, los padres se enfurecen contra los aduladores de la igualdad, por mor de mantener el rumbo cotidiano de las cosas. Pero si la misma inteligencia está en todos, tal como lo ven Deleuze y Jacotot, no hay más consecuencia que la emancipación, por un lado, y, por otro lado, el embrutecimiento por parte del maestro explicador. Es el maestro-tirano, aliado del método socrático, quien aliena y vuelve impotente la inteligencia del alumno.

Pero, ¿cómo es posible concebir una pedagogía sin método y sin maestro explicador? Los alumnos de Jacotot no sabían francés ni mucho menos escribir poemas de tan alta fuerza expresiva como los de los poetas de la época y, con todo y eso, lograron aprender francés y escribir versos; por lo tanto, Jacotot les enseñó algo. Pero, ¿qué? No les trasmitió su saber ni su ciencia, no les enseño reglas, métodos, no los embruteció con explicaciones que suspenden su poder de obrar y su inteligencia. Tan solo los puso en contacto con un libro y los mantuvo en la búsqueda de palabras, ritmos y diferencias. Podemos imaginar y recrear esos diálogos, pues son la esencia del libro de Jacotot. Les dice, lean, repitan y memoricen. Ahora les da otro libro, comparen las palabras, nuevamente escuchen la sonoridad, repitan, miren con sus propios ojos que hay cuatro filas, todos los versos se muestran así. Llegó el momento de comprender la voz que susurra en cada poema: ¿creen que está triste?, les pregunta Jacotot, ¿o, por el contrario, que es colérica o canta de alegría? ¿Ustedes qué piensan? La inteligencia que trabaja no es la del maestro, es la de los alumnos, a diferencia de Sócrates, Jacotot los fuerza a responder bajo sus propias capacidades. Los mantiene en un círculo del cual solo ellos podrán salir. "Hago lo que puedo para que mis alumnos sepan lo que ignoro. Es un crimen del que todos mis colegas en Europa deben buscar volverse culpables

44 Jacotot, D., Enseñanza universal: lengua materna, p. 295.

45 Ibid., p. 290. 
como yo. Nosotros profesores seríamos muy poco útiles si nuestros alumnos debieran saber solo lo que nosotros sabemos"46.

Jacotot se lamenta del embrutecimiento de los maestros. Y, aún más, de su egoísmo y ensimismamiento, pues se niegan a abrir mundos compartidos con sus estudiantes, a dejarse instruir y aprender de la mano de ellos. Cuando el maestro suspende su saber o no transmite su ciencia, pone en igualdad dos inteligencias, la de él y la del estudiante, y abre la posibilidad de que el infinito mundo de experiencias del estudiante, que comprende, imita, lee, y repite como aquel, se exprese, le llegue al corazón del maestro y tal vez lo afecte, lo conmueva y lo transforme. Esta forma de enseñanza permite un doble camino: las dos inteligencias aprenden, comparten, sueñan, dialogan y se reconocen en su igualdad. Por eso la suspensión del conocimiento del maestro es, para Jacotot, antes que nada, el inicio de un camino que se conduce de a dos, que libera dos inteligencias y las pone en un escenario donde las dos salen libradas de un juego movilizado por preguntas, y no, por el contrario, un obstáculo de la enseñanza y de la libre instrucción del maestro. Esa es la consecuencia y el sentido del maestro ignorante: suspender para liberar.

Jacotot mantiene a los estudiantes en la búsqueda de todo lo que contiene el libro, el Telémaco de Fenelón, y de los versos, después verificará si han prestado atención o no. Con otros libros les pedirá que comparen y que relacionen todo eso con otras cosas, con otros personajes, con otras aventuras, con su propia vida, con la geografia, con la historia, etcétera. No se precisa de un estudio especializado en cada rama, solo necesitan relacionar todo con todo y expresarlo con sus palabras: "Maestro: ¿Cuáles son los hechos que le han sugerido vuestras reflexiones sobre la modestia? Alumno: He leído el primer libro de Telémaco: -Con los ojos bajos, guardando un modesto silencio, Mentor seguia a Telémaco ${ }^{47}$. Maestro: expliquese. Alumno: Los ojos bajos, es una reserva en el porte; guardando silencio, es una reserva en las palabras, y seguía a Telémaco, es una reserva en las acciones. Maestro: ¿Y sobre la desconfianza? Alumno: Pigmalión era desconfiado, y Fenelón dice que él tenía miedo de su sombra, y que el menor ruido lo asustaba. Maestro: explíquese. Alumno: Él tiene miedo de su sombra, la toma por alguien que lo viene a degollar; está alerta al menor ruido, y se siente completamente conmovido, él cree escuchar los pasos de asesinos que buscan penetrar en sus aposentos para matarlo. Maestro: Continúen prestando atención a los hechos; aprenderán poco a poco

\footnotetext{
46 Ibid., p. 156.

${ }^{47}$ Las cursivas son palabras textuales del libro Telémaco.
} 
a conocer el verdadero sentido en el cual los franceses emplean sus palabras, y sabrán entonces ubicarlas convenientemente"48.

Nótese la forma tan diferente de preguntar del maestro liberador respecto a la del maestro tirano socrático. Aquí el maestro no presume de nada, solo quiere verificar lo que el mismo estudiante el capaz de pensar y expresar de acuerdo con los versos del Telémaco. La potencia y capacidad del estudiante se manifiestan en el poder de traducir las palabras del libro a las de su imaginación, en comprender el sentido de las expresiones francesas para poder entender y hablar el francés adecuadamente. El que busca encuentra, y el maestro sonríe al saber que su alumno está haciendo todo bajo su propio método, que él no interviene sino para adentrarse en el libro a través de las palabras y pensamientos de aquel, pues quiere ahondar en su inteligencia, quiere saber hasta dónde puede llegar a traducir los escenarios del libro, las peripecias del personaje, los sentimientos que expresa, etcétera. Rancière no se equivoca al decir con respecto a la enseñanza universal que "maestro es quien mantiene a quien busca en su camino, en donde él es el que busca y no deja de buscar"49.

Traducir e improvisar son las dos virtudes primarias de la inteligencia. El hecho de hablar y comprender por la palabra lo que otros dicen y piensan, lo inefable en los sentimientos o lo excelso que guarda un gesto, nos pone en una condición de atención y de búsqueda, de búsqueda de la palabra adecuada y de atención a lo expresado. Por eso, el estudiante pone a trabajar su inteligencia para adivinar lo que el poeta trata de expresar. El lenguaje metafórico lo fuerza de por sí a hacer las traducciones correctas, a abrir las palabras y escarbar las alusiones, los sentidos, las referencias expresas: he visto como el griego, las urbes de los hombres. Este verso nos lleva a imaginar toda una gama de posibilidades de traducción, encajarlo en un sentido, buscar en los griegos, mirar al tipo de hombre que guarda tras de sí un tiempo, etcétera. Una conversación se convierte también en una traducción y en una adivinanza.

Por tal razón las explicaciones y los métodos no son portadores de la inteligencia, sino tan solo procedimientos que la aíslan o, cuando menos, la dividen. Desde que se aprende la lengua materna ya se está aprendiendo una infinidad de cosas, por eso no hay ignorante que no sepa ya traducir y adivinar un verso o una conversación. Jacotot solo se sirve de un libro, de un objeto en común, que tanto él como el estudiante pueden explorar sin necesidad de método alguno. Pero en el libro está todo lo necesario para poner a trabajar la

48 Ibid., p. 56.

49 Rancière, J., El maestro ignorante, p. 65. 
inteligencia: cómo no estimular la imaginación si es necesario re-hacer una historia, traducir en imágenes al enorme insecto de Kafka, o el infierno de Dante, o el Aleph de Borges. Lo mismo sucede con una pintura o con una obra de teatro: el maestro debe estar dispuesto a poner un objeto común al servicio de la inteligencia, tiene que ofrecer los "encuentros" o los "tesoros" de los que habla Deleuze, infundir los signos, las preguntas, lanzar al agua al estudiante para que dinamice con un espacio.

En el segundo apartado hablamos del método de dramatización que propone Deleuze para ilustrar el proceso de actualización de una Idea o un virtual. Diríamos ahora que la dramatización es el método natural de la inteligencia que procede por diferenciación y no por imitación. Si el maestro le pide al estudiante que dibuje un paisaje o un retrato basándose en una imagen, sin proponerle método alguno, el estudiante tendrá, entonces, que tomarse su tiempo para empezar a dramatizar la Idea que tiene prevista: sabrá elegir el papel, el color del lápiz o el pincel, tratará de tantear el espacio, pondrá atención a la imagen, sus contornos, sus colores, a dónde se concentra la luz, etcétera. Todo esto es un drama que tendrá que superar por sí solo, por diferencias que observa en la imagen y las reproduce. El estudiante tendrá que devenir-pintor, esto es, tendrá que situarse en un territorio de vecindad en el cual lo único que ve son colores y líneas, diferencias de tonos, expresiones, gestos, contornos, y al mismo tiempo que borra, vuelve a pintar. El estudiante no imita la imagen porque él tiene que crear su propia figura. El maestro solo mantendrá al estudiante atento, que no se desvie: hace falta más color aquí, ¿ves una sombra o una línea?, etcétera.

Dicho todo esto, es fácil ver las consecuencias que se desprenden en términos políticos y ontológicos del recorrido aquí consignado. La suposición del método y de la enseñanza por parte del maestro explicador, que se funda en la desigualdad de las inteligencias, termina replicándose en la ficción social. Sin método y sin explicaciones, las masas seguirán siendo ignorantes, por ello es preciso del maestro-gobernante que las conduzca por el camino correcto y les muestre la verdad. Siempre se parte del mismo punto: hay ignorantes, gente inferior que necesita de explicaciones y de la ayuda de alguien para redimir su condición. Tanto Jacotot como Deleuze, que vivieron en contextos de agitación social y de energías revolucionarias, optan por seguir, pues, tal vez el camino que conduce más satisfactoriamente a la igualdad y a la emancipación. Este es precisamente el contrario del progreso social, en tanto es el que las considera como un punto de partida, como una tarea siempre a verificar en cada 
momento, en cada contexto, y no como su aplazamiento, como el ideal al que hay que llegar, mientras la lógica de la dominación avanza.

Recibido: 05/08/2020

Aceptado: 24/12/2020

\section{Bibliografia}

Bula, G., Spinoza: educación para el cambio, Bogotá: Aula de humanidades, 2017.

De Sousa Santos, B., La universidad en el siglo XXI, Buenos Aires: Miño y Dávila, 2011.

Deleuze, G., Diferencia y repetición, Buenos Aires: Amorrortu, 2002.

Deleuze, G., Dos regímenes de locos: textos y entrevistas (1975-1995), Valencia: Pretextos, 2008.

Deleuze, G., La isla desierta y otros textos: textos y entrevistas (1953-1974), Valencia: Pre-textos, 2005.

Freire, P., Pedagogía del oprimido. México D.F.: Siglo Veintiuno, 1977.

Habermas, J., Ciencia y técnica como ideología, Madrid: Tecnos, 1994.

Hawthorne, N., El holocausto del mundo, Bogotá D.C.: Norma, 1990.

Jacotot, J., Enseñanza universal: lengua materna, Buenos aires: Cactus, 2008.

Jaeger, W., Paideia: los ideales de la cultura griega, México D.F.: Fondo de Cultura Económica, 1995.

Lapoujade, D., Las existencias menores, Buenos aires: Cactus, 2017.

Martínez, J. E., La universidad productora de productores: entre biopolitica y subjetividad, Bogotá: Universidad de la Salle, 2010.

Nietzsche, F., El crepúsculo de los idolos, Madrid: Alianza Editorial, 1971.

Pardo, J. L., A propósito de Deleuze, Valencia: Pre-textos, 2014.

Platón, Menón, en: Diálogos, Olivieri, F.J. (trad.), v. II, Madrid: Gredos, 1983.

Proust, M., La muerte de las catedrales, Bogotá: Norma, 1993.

Rancière, J., El maestro ignorante: cinco lecciones para la emancipación intelectual, Buenos aires: Edhasa, 2018.

Souriau, E., Los diferentes modos de existencias, Buenos Aires: Cactus, 2017.

Stengers, I. y Latour, B., "La esfinge de la obra", en: Souriau, E. (ed.), Los diferentes modos de existencia, Buenos Aires: Cactus, 2017, pp. 7-92. 